DOI: $10.15826 /$ qr.2015.1.080

УДК 94(571):94(430) (091)

Клаус Штайнке

\author{
ЗАПИСКИ АВГУСТА ФОН КОЦЕБУ \\ О ТОБОЛЬСКЕ НАЧАЛА ХІХ В.: \\ К ВОСПРИЯТИЮ СИБИРИ НЕМЦАМИ
}

Klaus Steinke

\title{
TOBOLSK IN AUGUST VON KOTZEBUE'S SKETCHES: ON THE PERCEPTION OF SIBERIA BY GERMANS
}

The article considers a unique historical document - notes on the town of Tobolsk of the famous German writer and dramatist August von Kotzebue. Written in the early $19^{\text {th }}$ century, the notes reflect the peculiar character of Tobolsk; the author describes its nature, society, local elite that he became acquainted with during his two-week stay in the Siberian town. The author points out that the book enjoyed success with the public which was unusual for this modest work, and was published repeatedly in the $19^{\text {th }}$ and $20^{\text {th }}$ centuries. Kotzebue's work is compared with some later works of the literature of captives and travelers. The author of the article extensively quotes the source and analyzes its artistic and informational value. Additionally, he reveals the interest of the German society towards the remote region of Siberia conditioned by its fanciful nature, climatic anomalies, exoticism of its everyday life, on the one hand, and a desire to improve the cultural, and, potentially, economic contacts between the two countries on the other. According to the author, Kotzebue was the first to discover the image of Tobolsk and Siberia. His objective account of Russian hospitality and the goodwill of the population contrasted sharply with his description of the arbitrary rule of the Russian authorities and had a significant potential for the German cultural and economic circles. The article makes a professional review of the life of Kotzebue in German and Russian historiography; it also describes the position of the writer as to his condition of an exile and makes a description of his relationships with the locals, which adds to the already known biography of the playwright.

Keywords: August von Kotzebue; Tobolsk at the $19^{\text {th }}$ century, Siberia; memoires, banishment in Siberia

Предметом рассмотрения в данной статье является уникальный исторический документ - записки о городе Тобольске известного немецкого писателя и драматурга Августа фон Коцебу. Заметки, написанные в начале XIX в., открывают своеобразный облик Тобольска, автор описывает природу, общество, местную элиту, с которой он познакомился за 14 дней своего пребывания в сибирском городе. Отмечается небывалый для такого скромного сочинения успех книги, неоднократно переизданной в XIX 
и XX вв. Сочинение Коцебу сопоставляется с другими, более поздними произведениями «литературы пленных» и путешественников. Подробное цитирование источника сопровождается анализом художественных и информационных достоинств текста. Выявляется интерес немецкого общества к далекой Сибири, обусловленный причудливой природой, климатическими аномалиями, бытовой экзотикой, с одной стороны, и желанием продолжить и совершенствовать культурные, а возможно, в перспективе экономические контакты между двумя странами - с другой. Коцебу оценивается как первооткрыватель образа Тобольска и Сибири. Его объективные оценки русского гостеприимства, благожелательности населения резко контрастировали описанию произвола российской власти и были очень перспективны для немецких культурных и экономических кругов. Статья предлагает профессиональный обзор изучения судьбы Коцебу в немецкой и российской историографии; выявление позиции писателя к своему положению как ссыльного и описание взаимоотношений с местными жителями дают дополнительные штрихи к известной биографии драматурга.

Ключевые слова: Август фон Коцебу, Тобольск, Сибирь начала XIX в., ссылка в Сибирь, мемуары.

Немецкий писатель и драматург Август фон Коцебу (August Friedrich Ferdinand von Kotzebue) (1761-1819) в качестве ссыльного провел в 1800 г. около четырнадцати дней в Тобольске, прежде чем отправиться к пункту

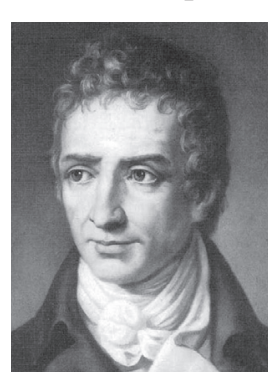
своего назначения - в Курган. Будучи одним из самых разносторонних и продуктивных немецких авторов XIX в., он, тем не менее, в настоящее время почти забыт в театральных кругах, несмотря на то, что им написано более двухсот пьес. При жизни он, однако, был знаменит и почитаем, прежде всего как драматург, не только в Германии, но и далеко за ее пределами. Его пьесы производили сильное впечатление на публику и переводились на многие языки. Ставили их не только на его родине, но и в России, Англии, Франции и странах Юго-Восточной Европы. Даже великий Гёте обращался к его творчеству как директор театра в Веймаре, где 87 его пьес игрались в общей сложности 600 раз. Произведения Коцебу неоднократно печатались.

Нельзя забывать и о его значении для развития русского театра того времени. Его пьесы, поставленные сначала в Москве и СанктПетербурге, а затем в других городах империи, в том числе и в Тобольске, потеснили доминировавший до тех пор французский репертуар ${ }^{1}$. В наше время они, однако, больше не ставятся и малоизвестны даже специалистам ${ }^{2}$, поэтому следует хотя бы в нескольких словах предста-

1 Немецкий славист G. Giesemann провел подробное исследование (1971) литературного восприятия Коцебу в России, проанализировав его значительное влияние на русский театр и полемику русских писателей с его творчеством [Giesemann].

${ }^{2}$ Российскими исследователями подробно прописан петербургский период жизни и творчества Августа Коцебу. См. работы о театральной деятельности немецкого автора: [Мельникова, 2004; Мельникова, 2012]. - Прим. ред. 
вить его весьма яркую и живую биографию, прежде всего чтобы лучше понять подоплеку его многомесячного пребывания в Сибири и значительный публицистический отклик на этот факт [см.: Giesemann, S. 169].

Август Фридрих Фердинанд фон ${ }^{3}$ Коцебу родился 3 мая 1761 г. в Веймаре, тогда крупнейшем центре немецкой культуры, в семье крупного чиновника при местном княжеском дворе. Уже в 16 лет он изучал юриспруденцию в университетах Дуйсбурга и Йены, а в 1780 г. получил высшее образование. Затем он открыл адвокатскую практику в своем родном городе и здесь же вскоре обратился главным образом к театру. Однако «Sein Witz und seine Spottlust trugen dem Zwanzigjährigen erste ärgerliche Reaktionen ein» ${ }^{4},-$ пишет Ханс Шуман [Schumann, S. 6] в своем предисловии к новому изданию путевых заметок Коцебу «Das merkwürdigste Jahr meines Lebens: Als Verbannter in Sibirien» ${ }^{5}$. Вероятно, поэтому ему и пришлось снова покинуть Веймар. Оттуда он направился в Санкт-Петербург, где был принят в Немецкий театр, писал пьесы и сам участвовал в их постановках. При Екатерине Великой он быстро сделал карьеру и в 1783 г. был назначен на должность судебного асессора в Ревале (Таллине), где продолжал заниматься театром. С 1790 г., когда умерла его первая жена, он начал заметно терять популярность и после едкой пьесы «Doktor Bahrdt» лишился благосклонности литературной сцены [Schumann, S. 15].

После второй женитьбы в 1794 г. он прожил три года в своем имении близ Нарвы. В этот период он написал много успешных пьес и в 1798 г. получил за это руководящую должность в венском Бургтеатре, от которой вскоре отказался, потому что разногласия с актерами отбили у него охоту к работе. Коцебу решил снова поехать в Россию, в Санкт-Петербург, чтобы увидеться со своими сыновьями от первого брака, которые воспитывались в кадетском корпусе. Он отправился в путь вопреки предостережениям о нестабильном положении, царившем при Павле I, который был настолько нежеланным наследником Екатерины, что в 1801 г. его убили. Поэтому в аресте Коцебу сразу по прибытии в Россию, несмотря на сопроводительное письмо и паспорт, было мало удивительного, хоть сам Коцебу этого совсем не ожидал. Непосредственно с границы ему пришлось начать свое вынужденное путешествие в Сибирь, о котором будет подробнее рассказано ниже. К счастью, его ссылка вскоре была отменена, и он смог наконец-то с четырехмесячным опозданием прибыть в Санкт-Петербург.

Несмотря на получение руководства тамошним театром и другие уступки со стороны царя, который хотел таким образом загладить несправедливость по отношению к Коцебу, тот в 1802 г. уехал в Берлин, а в 1805 г. - в Кёнигсберг. В этих городах он также работал для театра

\footnotetext{
3 Российское служилое дворянство он получил в 1785 г., став президентом губернского магистрата Эстонской губернии

4 «Его юмор и остроумие приносили двадцатилетнему юноше первые неприятные реакции». - Здесь и далее перевод цитат - автора статьи. - Прим. ред.

5 «Самый странный год моей жизни: как ссыльный в Сибири».
} 
и был издателем литературных журналов. После поражения Наполеона, с которым он вел ожесточенную публицистическую войну, в 1817 г. Коцебу стал русским генеральным консулом в Пруссии. Более того, при Александре I он взял на себя обязанность как «литературный корреспондент» тайно докладывать о культурной и политической жизни на Западе, из-за чего в нем вскоре заподозрили русского шпиона. В связи с этим опубликованные выдержки из украденных у него записок вызвали скандал. Эти серьезные обвинения в адрес Коцебу, однако, опровергаются: «Tatsächlich bestand das Verbrechen Kotzebues in nichts anderem als darin, daß er die politischen Anschauungen seiner Gegner nicht teilte - Grund genug, ihn der größten Untaten zu bezichtigen ${ }^{6}$ [Benz, S. 76]. В этой напряженной атмосфере 23 марта 1819 г. он был убит фанатичным студентом теологии Карлом Сандом в Маннхайме. Непосредственным мотивом этого преступления были критическая позиция Коцебу к либеральным идеям студенчества того времени и его язвительные насмешки над их искаженным национализмом ${ }^{7}$

Таким образом, Август фон Коцебу в свое время был известной личностью, поэтому его заметки о ссылке в Сибирь нашли широкий общественный отклик и стали «бестселлером» [Schumann, S. 6]. Эта книга была впервые издана уже в 1801 г., т. е. всего через несколько месяцев после его освобождения ${ }^{8}$, и уже в 1803 г. появилась в переработанной редакции ${ }^{9}$. С тех пор она публиковалась неоднократно, последним следует назвать издание 1989 г. $^{10}$, выпущенное известным швейцарским издательством Manesse [Kotzebue]. Это произведение в жанре путевых заметок, несомненно, имело значительный продолжительный отклик ${ }^{11}$ и оказало большое влияние на представление западных современников о России и Сибири. По сей день интерес к этому произведению не угас, если учесть, что даже в двадцатом веке оно было переиздано несколько раз (в том числе в 1918, 1958, 1989 гг.).

По содержанию книгу с первого взгляда, несомненно, можно отнести к жанру «литературы пленных и ссыльных», которая в России развила

\footnotetext{
${ }^{6}$ «На самом деле преступление Коцебу заключалось ни в чем ином, как в том, что он не разделял политических взглядов своих противников - причина достаточная для того, чтобы обвинить его в тяжелейших преступлениях».

${ }^{7}$ См. подробнее: [Заиченко]. Также см.: [Чебышев]. - Прим. ред.

${ }^{8}$ Это не удивительно, поскольку во время ссылки он мог делать объемные записи и таким образом ускорить последующую публикацию книги.

${ }^{9}$ Во второе издание не вошло «Краткое описание Михайловского дворца» и «Приложение о Mémoires secrets sur la Russie»- полемика с творчеством французского писателя Шарля Франсуа Филибера Массона [Schumann, S. 29].

$10 \mathrm{Ha}$ русском языке книга воспоминаний Коцебу в последнее время переиздавалась по крайней мере в 2001 г.: Коцебу, А. фон. Достопамятный год моей жизни : воспоминания / послесл. Г. Ратгауз. М. : Аграф, 2001. 314 с. - Прим. ред.

${ }_{11}^{11}$ Публицистический отклик на его ссылку не утихал до конца XIX в., когда С. Н. Мамеев в 1894 г. издал документы о пребывании Коцебу в Тобольске [Мамеев]. Кроме того, в 1891 г. этот случай был еще раз рассмотрен в журнале Hamburgischer Correspondent («Гамбургский корреспондент») [Giesemann, S. 170]. Перевод самих заметок на русский, выполненный В. Кряжевым, появился уже в 1806 г. [Достопамятный год], а в 1873 г. он был переиздан [см.: Giesemann, S. 172].
} 
собственную традицию от протопопа Аввакума до Евгении Гинзбург и Александра Солженицына и в которой описывается жизнь в сибирской ссылке или в местных лагерях. Сейчас примеры этого жанра есть и в Германии. К ним относится довольно известный, основанный на фактах роман Йозефа Мартина Бауэра «Soweit die Füße tragen» («Пока шагают ноги») (1955)12, дважды экранизированный (1963 и 2001 гг.). В нем описывается бегство Клеменса Форелла из советского лагеря для военнопленных. В 1949 г. ему удалось бежать от Берингова пролива на Кавказ, где он пересек персидскую границу. Эта история основана на реальных событиях, как и рассказ Августа фон Коцебу. Еще один автор, которого следует упомянуть в данном контексте, это, конечно, Хайнц Гюнтер Конзалик ${ }^{13}$, многочисленные романы которого, по единогласному мнению литературной критики, относятся к массовой литературе. Непосредственно о Сибири повествуют романы «Die Verdammten der Taiga» («Проклятые тайгой»), «Ninotschka, die Herrin der Taiga» («Ниночка - хозяйка тайги»), «Liebesnächte in der Taiga» («Ночи любви в тайге»), «Der Himmel über Kasachstan» («В небо через Казахстан») и др. По его романам о войне «Der Arzt von Stalingrad» («Врач из Сталинграда») (1958) и «Liebesnächte in der Taiga» (1967) были сняты фильмы. При сравнении его с Коцебу вырисовываются любопытные параллели. Конзалик тоже не воспринимается литературоведами всерьез как писатель, но имеет небывалый успех у публики на родине и за ее пределами. При жизни его 154 романа были переведены на 26 языков, было продано более 85 миллионов экземпляров его книг.

Если сравнить немецкие и русские произведения этого жанра, становятся очевидны специфические различия между ними. Немецкие ссыльные или военнопленные являются и остаются чужими в стране, ни языка, ни культуры, ни истории которой они не знают. Они находятся в совершенно чужом для них мире, в определенном смысле на другой «планете». Поэтому то, что их окружает, новые условия жизни они видят иначе, чем русские ссыльные, более острым взглядом. Соответственно некоторые их наблюдения точнее, но некоторые вещи они не понимают и не могут правильно оценить. При этом им обычно непонятны причины их приговора. В Сибири Коцебу постоянно, но безуспешно старается узнать истинную причину своей ссылки. Он находится в ситуации, известной нам по романам Франца Кафки, герои которого тоже пытаются понять свое положение, но вновь и вновь оказываются перед закрытой дверью и, не получая ясного ответа на насущный вопрос, могут только догадываться. Вопреки всем стараниям настоящая причина ареста и ссылки Коцебу в Сибирь останется скрытой от него и позже. В конечном счете до сих пор существуют

12 Очевидно, речь в нем идет о действительно существовавшем бывшем офицере вермахта Корнелиусе Росте (1922-1983), с которым писатель познакомился в Мюнхене.

13 Х. Г. Конзалик родился 28 мая 1921 г. в Кёльне и умер 2 октября 1999 г. в Зальцбурге. С 1939 г. он работал в гестапо, во время Второй мировой войны был военным корреспондентом во Франции и затем солдатом на Восточном фронте и получил тяжелое ранение в России. 
только предположения о подоплеке этого дела ${ }^{14}$. В связи с этим некоторые авторы поначалу вообще подвергали сомнению тот факт, что Коцебу был в ссылке и в Тобольске, поскольку якобы достоверных документов, подтверждающих это, нет ${ }^{15}$.

Коцебу - не первый немец, попавший в Сибирь и рассказавший об этом. Незадолго до него там побывали такие крупные исследователи, как Герхард Фридрих Мюллер (1703-1783) и Петер Симон Паллас (1741-1811), детально об этом написавшие. Но их научные произведения не достигли такого уровня известности и такой широкой публики, как история страданий арестованного и сосланного Коцебу. Конечно, его четырехмесячное пребывание в Сибири было относительно коротким, и у него не было научных амбиций в отношении своих заметок. Что касается внешних обстоятельств, ему, несомненно, повезло, потому что он был там в летние месяцы, т. е. в сравнительно приятное время года для Сибири, и относился, по собственному признанию, к привилегированной четвертой категории ${ }^{16}$ сосланных в Сибирь. Между тем его описание этой части Российской империи лишь в малой степени соответствует привычным для немецкой общественности представлениям о ней как об экзотическом, одновременно опасном и бескультурном крае, которые до сих пор распространены на Западе [Habeck, S. 161]. Одно упоминание слова «Сибирь» по сей день вызывает у многих ужас. Однако Коцебу занимают совсем другие проблемы, и для него на первом плане стоит не описание Сибири, а особые обстоятельства его ссылки, благодаря которым он там оказался, и его душевное состояние. Тем не менее его заметки содержат массу интересных для немецкого читателя деталей о стране и ее людях, сопровождавших его в ссылке.

Удивительно в его рассказе прежде всего то, что он выражается очень сдержанно и почти без критических нот, т. е. сознательно оберегает от любой критики того, по чьему приказу он был сослан в ссылку. "Viel auffälliger ist das positive Bild, das er, dem der Kaiser doch wahrlich übel mitgespielt hatte, von Paul zeichnet; fast überschwenglich rühmt er seine Gerechtigkeit und schiebt alle bösen Taten auf die elende Bürokratie. Es ist anzunehmen, daß Kotzebue das nicht ohne kluge Berechnung tat» ${ }^{17}$, - считает по этому поводу Х. Шуман [Schumann,

14 Более убедительно, чем гипотеза о подозрении Коцебу в якобинстве, звучит предположение о том, что на его примере хотели попросту дать наглядный урок и отпугнуть любых бунтовщиков от въезда в Россию [Giesemann, S. 170].

15 Этот пункт был, однако, окончательно разъяснен после публикации Мамеева (1894).

${ }^{16}$ К первой категории сосланных в Сибирь относились приговоренные судом тяжкие преступники, которых посылали на принудительные работы в кандалах и пешком. Вторую категорию составляли осужденные за более легкие преступления на поселение в Сибири; третью - ссыльные без каких-либо других ограничений; а четвертую, к которой причислял себя Коцебу, - сосланные туда без приговора по приказу монарха [Kotzebue, S. 238].

17 «Намного заметнее изображенный им положительный образ Павла, хотя император и сыграл с ним действительно злую шутку; почти экзальтированно славит он его справедливость и приписывает все дурные поступки презренной бюрократии. Следует предполагать, что Коцебу делал это не без умного расчета». 
S. 27]. В целом заметки «lebendig und frisch geschrieben, aber voll Eigenlob, Coquettiren mit seinen Gefühlen, Einmischung mystischer Geschichten und Hervorhebung politischer Anschauungen ${ }^{18}$, - пишет об этом произведении Людвиг Гейгер [Geiger, S. 772], тем самым объясняя еще одну причину столь широкого его распространения. Даже в наши дни это захватывающее, яркое и проникновенное произведение не потеряло своей притягательности для читателя, иначе бы Х. Шуман не переиздал его в 1989 г. «Кокетство с чувствами», конечно, вызвано и литературной модой того времени: сентиментализм хотя и прошел свой зенит, но путевые романы и романы в письмах по-прежнему находились под его влиянием.

В своих вплетенных в путевые заметки политических замечаниях Коцебу критикует прежде всего революционные идеи, антимонархические и демократические движения. Конечно, это делалось не только с тем намерением, чтобы не усугублять без нужды свое положение ${ }^{19}$. Несомненно, Коцебу писал так из внутренних убеждений, как покажет позже его критика либеральных идей студенческого движения. К тому же он не хотел, выражаясь современным языком, дополнительно портить имидж России, который и без того в Западной Европе складывался в то время не лучшим образом. Его убежденная приверженность по отношению к России, на службе которой он состоял долгое время, позднее выражалась в статьях для немецких журналов и во время его работы «литературным корреспондентом» на царя Александра I. Как решительный противник Наполеона и революции, он видел правильный путь в надежное будущее в «святом альянсе» империй. Прежде всего он полемизировал против широко распространенного мнения о том, что Россия займет место Наполеона и будет стремиться к гегемонии в Европе. Он неоднократно пытался опровергнуть неверные замечания о России в своем журнале Literarisches Wochenblatt [Benz, S. 78].

Несмотря на растущую критику в адрес Коцебу, которую обостряли его политические убеждения, история его ссылки очень быстро пробудила общий интерес. И здесь мы сосредоточимся на его замечаниях о Тобольске.

Они занимают центральное место в заметках, потому что Тобольск был первым городом, в котором он остановился на более или менее долгое время, где мог собрать и переработать основательные впечатления. Кроме того, Тобольск был той остановкой, где должна была решиться его дальнейшая судьба. Так что Коцебу приближается к этому городу с особенно тревожным предчувствием. К своему глубокому разочарованию, он скоро узнает, однако, что ему нельзя здесь остаться, что он должен ехать в удаленный от больших дорог город Курган.

\footnotetext{
18 «Написаны живо и свежо, но полны самовосхваления, кокетства с чувствами, примесей мистических историй и подчеркивания политических взглядов».

${ }^{19}$ Кстати, немного позже Александр фон Гумбольдт из политических соображений не написал собственного рассказа о своей поездке в Сибирь, потому что ему бы пришлось воздерживаться от любой критики социальных условий [Beck, S. 9]. Таким образом, рассказы о Сибири в XIX в. были далеко не беспроблемны для их авторов.
} 
Тем не менее губернатор Григорий Григорьевич Кошелев разрешил ему провести в Тобольске несколько дней и отдохнуть, прежде чем отправиться дальше к пункту назначения.

Очевидно, что у Коцебу нет ясного представления об истинном значении Тобольска для Сибири и России, которое подается лишь косвенно - например, в описании яркой рыночной жизни. Так, на «базаре» он находит не только отечественные, но и многочисленные импортные товары - из Европы и Китая. Кроме того, в многонациональном городе много ссыльных и заключенных. Все это, конечно, не удивительно, потому что Тобольск в то время был столицей Сибири и, соответственно, ее административным, экономическим и духовным центром. В непосредственной близости от современного Тобольска предводитель казаков Ермак одержал решающую победу над ханом Кучумом и тем самым утвердил господство России в Сибири. В 1587 г. здесь было основано первое укрепленное поселение, а затем построен единственный в Сибири кремль. Это поселение постоянно отстраивалось, и все важные пути из Европы на север, восток и юг Сибири до Тихого океана и Китая шли тогда через этот город. C XVIII по XIX в. Тобольск, как столица региона, был одновременно резиденцией генерал-губернатора, который отвечал в том числе за распределение заключенных и ссыльных. Поэтому Коцебу должен был прибыть сюда и отметиться, как это делали многие до и после него - как, например, протопоп Аввакум и Радищев, декабристы и Достоевский. Все это демонстрирует значение Тобольска как политического и духовного центра новой территории на востоке, где в 1705 г. был основан первый театр.

На первом плане описания поездки Коцебу стоят, однако, не исторические и прочие факты о Сибири, а знакомство со ссыльными разных общественных слоев и национальностей, чьи образы и режим содержания которых он рисует довольно подробно и детально. Эпизоды выдержаны в стиле того времени. Коцебу был не сторонним наблюдателем, а чувствительным путником, который внимательно описывает настроения и рассказывает читателю о своем собственном мире чувств. Показательна в этом смысле сцена въезда в Тобольскую губернию. Едва оказавшись на этой территории, он встречает старика, который живет здесь вот уже больше тридцати лет, из-за чего тронулся рассудком. Он просит у Коцебу, совершенно незнакомого человека, письмо от своей семьи в Ревале. Этот случай, конечно, сразу напоминает Коцебу его собственную судьбу и толкуется как дурное предзнаменование. Описывая этот момент, он пытается донести до читателя прежде всего свое собственное состояние духа, выразить свои тревожные ожидания перед прибытием в Тобольск. Этот эпизод настолько хорошо вписывается в эмоциональный контекст «сентиментального путешествия» в традиции Л. Стерна, что можно усомниться в его достоверности. Конечно, Коцебу не только «кокетничал» с чувствами, но действительно был полон отчаяния, тем более что причина его ссылки по-прежнему оставалась ему неизвестна. Это не мешало ему как 


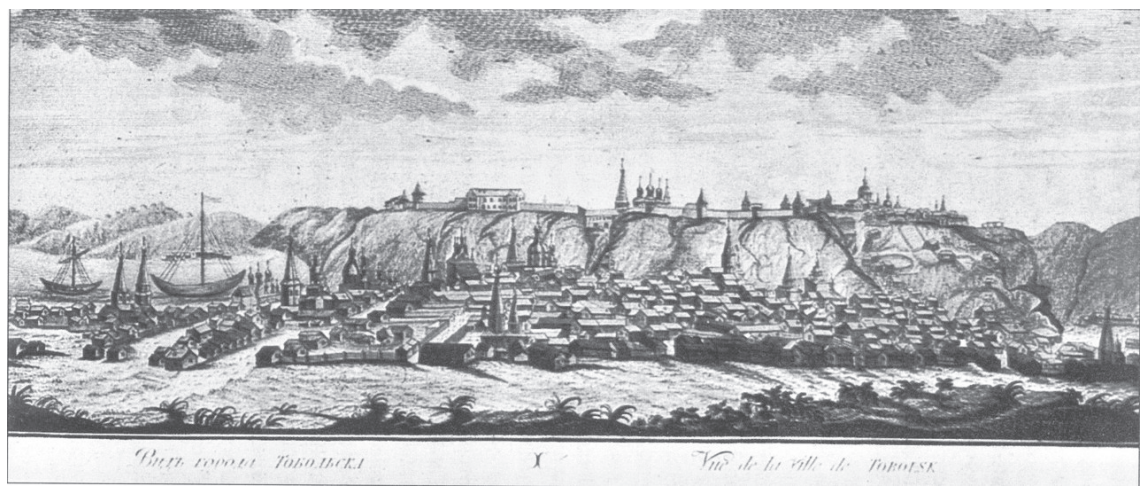

Вид на Тобольск. Гравюра XVIII в. Частное собрание

внимательному наблюдателю сообщать читателю свои впечатления от страны и ее населения. Первое впечатление о Тобольске он получает сидя в лодке, потому что из-за сильного наводнения в город было не добраться по суше. С реки ему открывается живописная панорама города на крутом береге Иртыша с многочисленными церквями, кремлем и губернаторским дворцом на возвышенности. Эту живописную общую картину нарушают только развалины сгоревшего дворца.

Губернатор Тобольска описывается как очень симпатичный, отзывчивый и образованный человек, который, в отличие от его прежнего, совершенно необразованного сопровождающего и охранника, надворного советника Щекатихина, говорит по-французски. Эта встреча оказывается приятной неожиданностью для них обоих: для губернатора, который знал писателя Коцебу, но понятия не имел, что он и доставленный к нему ссыльный - это одно лицо; и для Коцебу, обнаружившего, что губернатор не только знал о нем как о писателе, но и читал его произведения: «...und, die Wahrheit zu gestehn, mir selbst war es höchst unerwartet, in einem so entfernten, rauhen Erdwinkel so viele Bekannte, ja, ich darf sagen, so viele teilnehmende Freunde zu finden» [Kotzebue, S. 213 $]^{20}$. Конечно, это было неожиданностью и для немецкого читателя, который, как и Коцебу, изначально имеет о далекой Сибири совершенно другие представления и не ожидает найти здесь разнообразной и живой культурной сцены, которая к тому же почти не уступает немецкой. Образованным кругам в Тобольске Коцебу, следовательно, был известен, а его пьесы, как он скоро выяснил, уже давно шли в местном театре. Вообще, общественная жизнь здесь кажется очень насыщенной. Кроме театра есть казино, где в числе прочего проводятся балы-маскарады, в которых Коцебу, однако, участия не принимает. Эти мероприятия устраиваются по преимуществу многочисленными ссыльными, которые могут довольно свободно передвигаться и образуют общность, объединенную

\footnotetext{
20 «...и, признаться, для меня самого было в высшей степени неожиданностью на таком далеком, суровом клочке земли найти так много знакомых, да и, могу сказать, так много участливых друзей».
} 
культурными интересами. Новость о прибытии Коцебу молниеносно распространилась среди них, и они тут же засвидетельствовали ему, известному и популярному писателю, свое почтение. Хоть он и утверждает, что это внимание было ему обременительно, он все же чувствует себя вполне польщенным.

Рассказы о его экскурсиях по окрестностям не отличаются детальностью. Из них читатель узнает только, что окрестности эти составляют бесконечные леса и речное русло со скалами - и все очень живописно. Значительно подробнее описан город, который своими широкими и прямыми улицами производит благоприятное впечатление. Коцебу подчеркнуто хвалит чистоту выстеленных досками тротуаров. Кроме многочисленных деревянных домов в городе есть и несколько солидных каменных зданий, которые свидетельствуют о наличии состоятельного среднего слоя. Центр города образует пестрый рынок со своей многонациональной клиентурой. Особенно поражают Коцебу рыбные ряды и их богатый, преимущественно из окрестных водоемов ассортимент. В целом от этих зарисовок у читателя создается вполне положительное впечатление от города и его населения.

Только при описании климатических условий Коцебу затрагивает менее приятные аспекты, такие как невыносимая жара и комары летом, что было испытано им самим, и суровый холод зимой, при котором замерзает даже ртуть. Однако он находит во всем этом и позитивную сторону: «Übrigens ist dieses rauhe Klima ist sehr gesund. Mein Arzt kannte nur zwei herrschende Krankheiten die sich leicht vermeiden lassen. Die eine ist die Lustseuche; die andere sind häufige Erkältungsfieber» ${ }^{21}$. В отвратительном климате заключается и причина скудной растительности. Здесь нет фруктовых деревьев, только крушина, желтая акация и березы. Кроме этого он обнаруживает в саду губернатора кусты смородины и крыжовника, капусту и огурцы. Зато это благоприятные условия для выращивания злаков, особенно гречихи, которая дает богатый урожай на плодородном черноземе. Эту землю не надо удобрять, что, по его словам, приводит в деревнях к значительным проблемам, потому что крестьяне из лени оставляют навоз лежать в хлевах, пока там не станет настолько невыносимо, что они в конце концов сносят дома и уезжают дальше. Описание флоры не отличается ни точностью, ни полнотой, и Коцебу предстает перед читателем как «дилетант в ботанике».

В том, что заметки Коцебу были и остаются весьма популярными, заслуга не только самой истории, но и писательского таланта автора. Он знает, как захватить читателя своей волнующей историей и одновременно создать обширную и реалистичную панораму природы, климата, условий жизни в Сибири и населяющих ее людей. В этом отношении его воспоминания внесли большой вклад в объективизацию образа Сибири у немецкого читателя - возможно, даже больший, чем

21 «Впрочем, этот жесткий климат очень здоровый. Мой врач знал только две распространенные болезни, которых можно легко избежать. Одна - дурная болезнь, другая - частая простудная лихорадка». 
научные работы, которые не достигли широкой публики. Хотя издатель и характеризует это произведение как «потрясающий документ о произволе в царстве», в чем он, конечно, прав, особенно в отношении правления Павла I, но при этом Коцебу все же рисует очень детальную картину. Поразительно, что, несмотря на свое трудное положение, он не опускается до жалобных песен, а довольно трезво представляет условия жизни и подчеркивает в первую очередь гостеприимство и готовность помочь среди местных жителей, которые совсем не относятся к нему, ссыльному, как к преступнику или прокаженному. Наверняка его тесные связи с Россией уберегли его от того, чтобы своим произведением укрепить общую современную неприязнь к ней. Особое стремление Коцебу к разумному изображению российской действительности подчеркивает относительно его последующей журналистской деятельности исследователь: «...nichts unter diesen Nachrichten < die Rußland betreffen>, aber ist der Art, daß es die Absicht verriete, Rußland einen besonderen kulturellen oder politischen Einfluß in Deutschland einzuräumen. Vielmehr bemühen sich diese Nachrichten Kotzebues, eine Reihe von zeitgenössischen deutschen Vorurteilen über Rußland zu beseitigen...» ${ }^{22}$ [Benz, S. 71]. Коцебу можно назвать не только хорошим примером объективизации образа Сибири у немцев, но и активным первопроходцем в разумном развитии немецко-российского культурного обмена.

\section{Список литературы}

Достопамятный год жизни Августа Коцебу, или заточение его в Сибирь и возвращение оттуда, писано им самим, переведено с немецкого В. Кряжевым. В 2-х ч. М., 1806 ; 2-е изд. М, 1816.

Заиченко О. В. Август фон Коцебу: история политического убийства // Новая и новейшая история. 2013. № 2. С. 177-191.

Мамеев С. Н. Документы, относящиеся к ссылке Августа Коцебу в Сибирь в 1800 году // Ежегодник Тобольскаго губернскаго музея. 1894. Вып. 2. С. 1-10.

Мельникова С. И. Август Коцебу в Санкт-Петербурге. Линии судьбы немецкого драматурга [Электронный ресурс] // Немцы в Санкт-Петербурге. Биографический аспект. XVIII-XX вв. Вып. 7 / Рос. акад. наук, Музей антропологии и этнографии им. Петра Великого (Кунсткамера); [отв. ред. Т. А. Шрадер]. СПб. : МАЭ PAH, 2012. 364 с. URL: http://www.kunstkamera.ru/files/lib/978-5-88431-208-1/978-5-88431-208-1_02.pdf.

Мельникова С. И. Август фон Коцебу в России : К проблеме русско-немецких театральных связей: дис. ... д-ра искусствоведения [Электронный ресурс]. СПб., 2004. URL: http://www.dissercat.com/content/avgust-fon-kotsebu-v-rossii-k-problemerussko-nemetskikh-teatralnykh-svyazei.

Чебышев А. А. Драма в Мангейме. (К биографии Коцебу) // Голос минувшего. 1913. № 2. C. $40-81$.

Beck $H$. Einführung // Alexander von Humboldts Reise durchs Baltikum nach Rußland und Sibirien 1829. Stuttgart, 1984.

Benz E. Franz von Baader und Kotzebue. Das Rußlandbild der Restaurationszeit // Abhandlungen der Geistes- und Sozialwissenschaftlichen Klasse Jg. 1959. № 2:. S. 61-99.

Geiger L. Kotzebue, A. v. K. // Allgemeine Deutsche Biographie. 1882. Bd. 16. S. 772-780.

Giesemann G. Kotzebue in Rußland. Materialien zu einer Wirkungsgeschichte. Frankfurt a. M., 1971.

22 «..но ни одно из этих сообщений <касающихся России> не выказывает намерения приписать России особое культурное или политическое влияние на Германию. В гораздо большей степени эти сообщения Коцебу стараются устранить ряд современных немецких предрассудков о России...» 
Habeck J. O. Kulturlandschaft Sibirien [Electronic resource] // Jahrbuch des MaxPlanck-Instituts. 2005. S. 161-166. URL: http://www.mpg.de/863491/forschungsSchwerp unkt1?c=166398.

Kotzebue A. von. Das merkwürdigste Jahr meines Lebens. Als Verbannter in Sibirien / Hrsg., Einf. H. Schumann. Zürich : Manesse Verlag, 1989.

Schumann H. Einführung // Kotzebue A. von. Das merkwürdigste Jahr meines Lebens. Als Verbannter in Sibirien. Zürich : Manesse Verlag, 1989.

\section{References}

Beck, H. (1984). Einführung. In Alexander von Humboldts Reise durchs Baltikum nach Rußland und Sibirien 1829. Stuttgart.

Benz, E. (1959). Franz von Baader und Kotzebue. Das Rußlandbild der Restaurationszeit. Abhandlungen der Geistes- und Sozialwissenschaftlichen Klasse Jg., 2, 61-99.

Cheby'shev, A. A. (1913). Drama v Mangejme. (K biografii Kocebu) [Drama in Mannheim. (On the biography of Kotzebue)]. Golos minuvshego, 2, 40-81.

Dostopamyatny'j god zhizni Avgusta Kocebu, ili zatochenie ego v Sibir' I vozvrashhenie ottuda [A Memorable year of August Kotzebue's life, or imprisonment in Siberia and his return from there]. (1806; $2^{\text {nd }}$ ed. 1816). (Part 1-2). Moscow.

Geiger, L. (1882). Kotzebue, A. v. K. In Allgemeine Deutsche Biographie (Bd. 16, pp. 772-780).

Giesemann, G. (1971). Kotzebue in Rußland. Materialien zu einer Wirkungsgeschichte. Frankfurt a. M.

Habeck, J. O. (2005). Kulturlandschaft Sibirien. In Jahrbuch des Max-Planck-Instituts. S. 161-166. Retrieved from: http://www.mpg.de/863491/forschungsSchwerpunkt1 $? \mathrm{c}=166398$.

Kotzebue, A. von. (1989). Das merkwürdigste Jahr meines Lebens. Als Verbannter in Sibirien. Zürich: Manesse Verlag.

Mameev, S. N. (1894). Dokumenty', otnosyashhiesya k ssy'lke Avgusta Kocebu v Sibir' v 1880 godu [Documents related to August Kotzebue's exile to Siberia in 1800]. In Ezhegodnik Tobol'skago gubernskago muzeya (Vol. 2, pp. 1-10).

Mel'nikova, S. I. (2004). Avgust fon Kocebu v Rossii: K probleme russko-nemeczkih teatral'ny'h svyazej: diss. ... d-ra iskusstvovedeniya [August von Kotzebue in Russia: On the problem of Russian-German theater relations]. (Dissertation). Saint Petersburg. Retrieved from: http://www.dissercat.com/content/avgust-fon-kotsebu-v-rossii-k-problemerussko-nemetskikh-teatralnykh-svyazei.

Mel'nikova, S. I. (2012). Avgust Kocebu v Sankt-Peterburge. Linii sud'by' nemeczkogo dramaturga [August Kotzebue in Saint Petersburg. Destiny lines of a German playwright]. In Shrader T. A. (Ed.). Nemcy'v Sankt-Peterburge. Bibliograficheskij aspekt. XVIII-XX $v v$. (Vol. 7). Saint Petersburg. Retrieved from: http://www.kunstkamera.ru/files/lib/978-588431-208-1/978-5-88431-208-1 02.pdf.

Schumann, H. (1989). Einführung. In Kotzebue, A. von. Das merkwürdigste Jahr meines Lebens. Als Verbannter in Sibirien. Zürich: Manesse Verlag.

Zaichenko, O. V. (2013). Avgust fon Kocebu: istoriya politicheskogo ubijstva [August von Kotzebue: A story of political assassination]. Novaya i novejshaya istoriya, 2, 177-191.

The article was submitted on 03.02.2015

\section{Клаус Штайнке,}

д. и. н., профессор, Университет Эрлангена Нюрнберга,

Эрланген, Германия

klaus-steinke@web.de
Klaus Steinke, Dr.

Professor,

University of Erlangen-Nuremberg,

Erlangen, Germany

klaus-steinke@web.de 